\title{
Hermenéutica dialógica: claves para pensar la escucha en la educación
}

Primer semestre de 2019 - pp. 71-81 Segunda época

N.o 10
Dialogical

Hermeneutics: Keys to

Think about Listening

in Education
Hermenéutica

dialógica: chaves para

pensar a escuta na

educação
Para citar este artículo

León Suárez, J. (2019). Hermenéutica dialógica: claves para pensar la escucha en la educación. Folios, 49, 71-81. doi: 10.17227/Folios.49-9392

Juliana Patricia León Suárez* Orcid: https://orcid.org/0000-0002-3592-5228

Artículo recibid

$27 \cdot 08 \cdot 2017$

* Estudiante del Doctorado Interinstitucional de Educación DIE-UD. Magíster en Investigación Social Interdisciplinaria. Docente de Lenguaje de la Facultad de Artes, Universidad Distrital Francisco José de Caldas.

Artículo aprobado $20 \cdot 06 \cdot 2018$ 


\section{Resumen}

Este artículo de reflexión se plantea como un viaje transformador en sí mismo. Forma parte de la investigación doctoral en curso: “Configuraciones didácticas necesarias para el desarrollo de las semio-discursividades de la escucha en diversos contextos", de la Universidad Distrital Francisco José de Caldas, adscrita a la alianza AIDETC-COLCIENCIAS. Su objetivo es mostrar la necesidad de la formación de la escucha en la educación desde una perspectiva hermenéutica dialógica. Para ello, se sitúa en la Bildung alemana, la hermenéutica de Gadamer y las propuestas dialógicas de Bajtín, Buber y Ponzio, principalmente. Estos se constituyen en paradigmas claves para promover una pedagogía del espíritu cuyo núcleo y razón de ser es la escucha, que el documento presenta de manera progresiva, a través de seis apartados. Se concluye con la necesidad de formar y formarnos en la comprensión del sí mismo, del otro y de lo otro, la tríada de una escucha arquitectónica, hermenéutica y dialógica que nos llama a practicar la pedagogía del espíritu, la pedagogía de la escucha.

\section{Palabras clave}

escucha; comprensión respondente; arquitectónica; formación

\section{Abstract}

This reflection paper is a transformative journey in itself. It is part of the ongoing doctoral research titled "Necessary didactic configurations to develop semi-discursive listening in different contexts" of Universidad Distrital Francisco José de Caldas and part of the AIDETC-COLCIENCIAS alliance. The goal is to show the need for training in listening in education from a dialogical and hermeneutic perspective. For that purpose, the research is mostly based on the German Bildung, Gadamer's hermeneutics, and the dialogic proposals of Bakhtin, Buber and Ponzio. These are key paradigms to promote a pedagogy of the spirit, whose core and reason for being is listening, something that the document develops progressively over the course of six sections. The paper concludes with the need to train ourselves and others to understand ourselves as well as others, the triad of an architectural, hermeneutic and dialogical listening that encourages us to practice the pedagogy of the spirit,

the pedagogy of listening.

\section{Keywords}

listening; respondent understanding; architectural; training

\section{Resumo}

Este artigo de reflexão é exposto como uma viagem transformadora em si mesmo. Faz parte da pesquisa doutoral em curso “Configurações didáticas necessárias para o desenvolvimento das semio-discursividades da escuta em diversos contextos", da Universidade Distrital Francisco José de Caldas, vinculada à aliança AIDETC-COLCIENCIAS. Seu objetivo é evidenciar a necessidade da formação da escuta na educação desde uma perspectiva hermenêutica dialógica. Para isso, situamos na Bildung alemã, a hermenêutica de Gadamer e as propostas dialógicas de Bajtín, Buber e Ponzio, principalmente. Aqueles se constituem em paradigmas chaves para promover uma pedagogia do espírito cujo núcleo e razão de ser é a escuta, que no documento apresenta de forma progressiva, através de seis seções. Concluímos com a necessidade de formar e nos formar na compreensão do si mesmo, do Outro e o outro, a tríada de uma escuta arquitetónica, hermenêutica e dialógica que nos convida a praticar a pedagogia do espírito, a pedagogia da escuta.

\section{Palavras-chave}

escuta; compreensão respondente; arquitetónica; formação 
Ítaca

(Fragmento)

Cuando emprendas tu viaje a Ítaca pide que el camino sea largo, lleno de aventuras, lleno de experiencias. No temas a los lestrigones ni a los cíclopes ni al colérico Poseidón, seres tales jamás hallarás en tu camino, si tu pensar es elevado, si selecta es la emoción que toca tu espíritu y tu cuerpo. $\mathrm{Ni}$ a los lestrigones ni a los cíclopes ni al salvaje Poseidón encontrarás, si no los llevas dentro de tu alma, si no los yergue tu alma ante ti.

\section{Constantino Cavafis}

Cuando nos embarcamos en la aventura de pensar la escucha en la educación, encontramos los aportes de la hermenéutica gadameriana, por un lado, y la dialógica bajtiniana, por el otro. Hoy las aguas de esa búsqueda nos han hecho descender de vez en cuando en algunas costas, para reflexionar el porqué de una propuesta afincada en el diálogo. Con este artículo justificamos una hermenéutica dialógica, más que dialéctica, cuyos sentidos aporten a la construcción de un marco sobre la necesaria formación de la escucha en la escuela desde importantes intersecciones entre Bajtín, Gadamer y Buber, principalmente. Las rutas que hemos trazado para este viaje apenas son posibilidades de descubrimiento de nuevas tierras, pues implica ver con ojos nuevos lo ya visto, es decir que no constituyen un análisis exhaustivo, sino que más bien son una provocación; una exploración de los pilares sobre los cuales se desarrolla la investigación doctoral "Configuraciones didácticas necesarias para el desarrollo de las semiodiscursividades de la escucha en diversos contextos educativos". Esperamos que el lector disfrute del periplo y regrese enriquecido a Ítaca.

\section{Breve contexto: la formación en las ciencias del espíritu}

Para formular una pedagogía hermenéutica dialógica, hemos tomado como referencia a Conrad Vilanou (2002), quien nos presenta los orígenes de la Bildung y nos insta a repensarla. Él recurre no solo a la hermenéutica sino a la visión neo-hebraica de Martín Buber, ya que "sólo se puede aprender a través de la conversación" (Vilanou citando a Buber, 2012, p. 219). Por medio de este investigador catalán nos remontarnos a una tradición neohumanista de lo que ha sido llamado por la filosofía alemana Bildung, planteada desde el idealismo de Hegel; el historicismo de Dilthey; las ciencias del espíritu con Spranger, Litt y Flirner; y los aportes de Heiddeger, para ser recogidas por Gadamer en la contribución de su hermenéutica y la dimensión dialógico-comunicativa del siglo xx. La Bildung se remonta más allá del Renacimiento alemán. Se nos relata cómo el retorno a la antigua Grecia es el primer referente para la emergencia de las ciencias del espíritu, así como el Bildungsideal en la Edad Media de Eckhart, y más tarde, la crisis de la modernidad que deseaba volver a esos ideales. Conrad Vilanou (2002) enfatiza en que ese ideal de la Bildung alemana es la línea de fuerza que transita la pedagogía contemporánea, Bildung que constituye un proyecto de cultura general humana, un proyecto de individuación.

Si la Bildung no se traduce directamente como formación -aunque así se le ha acuñado al español-, es por su cercanía al concepto de cultura. Junto con Geist (espíritu) y Freihgeit (libertad), se configura una pedagogía que "atiende a la plenitud de lo humano en el hombre" (Vilanou, 2002, p. 206). La idea de libertad se funda en Kant, por la formación de la cultura y la razón. El ideal descansa en un hombre culto, modelo del hombre burgués, portador de los valores humanistas y románticos. De esta forma, se nos muestra una gran tradición filosófica que explota con el neohumanismo y su bandera de progreso de la humanidad bajo la dirección de los grandes eruditos alemanes como Kant, Shiller, Höldering, Goethe, Hegel, entre muchos otros. Para este caso, nos interesa la Bildung hegeliana porque esta se configura como reflejo de la relación entre un mundo espiritual, de valores objetivos y la individualidad formada. El espíritu humano (Geist) es el valor paradigmático, la esencia de la historia para Hegel. Es sobre el cual se funda un horizonte 
teleológico ${ }^{1}$ porque es ahí donde se da el despliegue de la historia. En resumen, para Hegel, tal como lo entiende Vilanou (2002), el universo se divide en la naturaleza física y el mundo espiritual. Este último es el núcleo, el corazón de la historia. Hegel muestra cómo desde la naturaleza física se incluye al hombre en el proceso del espíritu, esto es, en el proceso de Bildung. Cabe, entonces, preguntar, ¿ es esta la primera pista para pensar una formación de la escucha en la escuela?, ¿acaso nacida de las Ciencias del Espíritu, en el seno de un proyecto de lo humano?

\section{Hermenéutica dialógica: convergencias entre Gadamer y Bajtín}

\begin{abstract}
Así pues, Hegel -para quien lo verdadero es la totalidad-utiliza el círculo para representar la figura dinámica del espiritu absoluto en su camino desde sí mismo a sí mismo, de modo que la formación exige la inclusión del hombre en el proceso del espiritu, quedando asegurada la concatenación interna del círculo mediante la dialéctica.
\end{abstract}

Vilanou (2002, p. 207).

El círculo que representa el movimiento del espíritu no es otra cosa que un periplo. Este es el viaje que todos hacemos y que nos permite entender que la formación es el encuentro consigo mismo, un viaje de retorno del que se llega enriquecido. Para explicarlo, nada mejor que la Odisea, de Homero, que hemos escogido por dos cuestiones: revela la importancia, expresada por Hegel, acerca de los clásicos griegos en la formación humana y es uno de los antecedentes de la Bildungsroman.

Odiseo está enfermo de nostalgia y anhela el regreso a Ítaca, a Penélope, a Telémaco. Todos conocemos la historia, la formación del héroe que se va dando a partir de las adversidades del camino, de sus encuentros, enfrentamientos y conversaciones con Poseidón, Polifemo, Calipso, por nombrar algunos; los cambios que se producen en sí mismo.

1 La referencia a la teleología tiene que ver con los propósitos o causas finales de la transformación del sujeto. Nuestra interpretación es que el sujeto en formación es inconcluso, siempre deviene y su transformación es un proceso que se explica a la manera de Foucault con la experiencia de sí o a través de la pregunta de Nietszche: “Cómo he llegado a ser lo que soy?" (Gómez, 2013, p. 39).
Alguien se referirá a la transformación física del rey de Ítaca en un miserable mendigo, pero esto no es más que la ayuda de Atenea para despistar a los pretendientes de Penélope y permitirle a Odiseo que retome su lugar. La verdadera transformación está en el interior del héroe que, una vez reconocido por sus enemigos, tiene conciencia de sí mismo y de su evolución durante la larga temporada de ausencia. Por eso, la apropiación de la experiencia y la autoconciencia es el abandono del estado natural para alcanzar el mundo espiritual, en lo que Hegel llama un ideal inacabado.

En el movimiento del espíritu que expone Vilanou (2002) advertimos un círculo hermenéutico de la comprensión de sí mismo, que para Hegel es el cultivo de sí. Este último implica un camino interior, espiritual, que eleva la condición humana y nos emancipa. Para Hegel (citado por Vilanou, 2002) es el desarrollo autoformativo, un proceso dialéctico y biográfico. Biográfico, porque implica un devenir espiritual; dialéctico, porque la vida humana se da en la historia, en lo otro. Puede decirse, entonces, que la metáfora es más bien una espiral continua. El centro de estas ciencias espirituales es comprender, captar la vivencia humana, su Erlebnis, su amplitud y complejidad. Si antes se fragmentó el ser humano y el conocimiento, estas ciencias buscarán el todo global de la vida humana, es decir, la historia.

Sin embargo, en toda esta vuelta, hace falta un giro que reconozca con mayor profundidad la alteridad, además de la historia. Para Vergara (2011), Gadamer impulsa el giro hermenéutico de la filosofía contemporánea a partir de la categoría dialógica, considerándola fuente de significación por explorar y explotar, en la que la hermenéutica como autocomprensión es la comprensión del propio ser como ser-en-el-mundo. Así como Odiseo no puede ser lo que es sin aquellos que lo han construido, tampoco puede obviarse la construcción de los otros por él mismo. La toma de conciencia de sí y la autocomprensión se dan en el mundo de la vida, en la presencia de ese ser, en cuanto:

[...] me conozco y llego a ser yo mismo sólo al manifestarme para el otro, a través del otro y con la ayuda del otro. Los actos más importantes que 
constituyen la autoconciencia se determinan por la relación con la otra conciencia. (Bajtín, citado por Alejos, 2006, p. 47).

Tanto la propuesta arquitectónica bajtiniana como la hermenéutica de la comprensión de Gadamer tienen posibles intersecciones que permiten enmarcar el fenómeno y el campo de esta investigación: la escucha. ¿Es posible una hermenéutica dialógica, más que dialéctica? ¿Para qué enunciarla de ese modo? ¿Qué impacto arroja una hermenéutica dialógica sobre la concepción de la escucha?

Intentemos evidenciar algunas convergencias que se acerquen a posibles respuestas y nos permitan orientar la ruta: i) la condición universal de la comprensión dada en la historia o en lo otro, en una arquitectónica de alteridad y de sí mismo; ii) la fusión de horizontes y la exotopía para fundamentar el diálogo; y por último, iii) el diálogo más allá de la palabra y como formación para la escucha en cuanto acto responsivo y comprensivo.

\section{Condición universal de la comprensión y arquitectónica bajtiniana}

Tanto la propuesta de Gadamer (2004) como la de Bajtín (2015) poseen un carácter dialógico que reconoce principios fundamentales. Del primero, puede decirse que califica la experiencia humana del mundo en general como hermenéutica, dada nuestra constante necesidad de orientarnos, de comprender, porque "la comprensión va ligada al lenguaje" (Gadamer, 2004, p. 233) y vivimos en él sin que ello sea relativista. Para Gadamer (2004) existe un proceso hermenéutico continuo,

[...] un mundo que ya se ha interpretado a sí mismo, un mundo ya cohesionado en sus relaciones, en el cual entra la experiencia como algo nuevo que trastoca lo que había guiado nuestras expectativas, y que al trastocarse se ordena de nuevo [...] el asentamiento en lo familiar y en el consenso permite la salida a lo extraño, la recepción de lo ajeno y por ende la ampliación y el enriquecimiento de nuestra propia experiencia del mundo. (p. 233).
Es interesante observar cómo para el autor alemán el movimiento hacia el otro pareciera salir primero de sí mismo para luego reconocer la alteridad en la propia experiencia, que se enriquece y actualiza cada vez con lo ajeno. También es evidente el mundo ya existente en tanto Historia que ha estado en el proceso continuo de comprensión e interpretación y en la que nos inscribimos en el momento mismo de ser-en-elmundo. Gadamer (2004) no solo señala el consenso, sino el malentendido y la extrañeza que nos mueve a la comprensión y la búsqueda de sentido. La lengua es aquí entendida no solo como un sistema de signos sino en la infinitud que constituye un diálogo diverso, relacionado con otras culturas y otras lenguas, en el principio de inagotabilidad de la palabra.

Por eso mismo, complementamos la propuesta hacia la teoría de Bajtín (2015) que va en vía inversa: del otro al yo, en lo otro o en el mundo de la vida, porque Bajtín reconoce la Historia en la que nos inscribimos. Igualmente, el lenguaje en la extensión de su multidimensionalidad y no solo de la palabra, en su polifonía, en el sentido y la compresión como condición de universalidad en la arquitectónica del mundo de la vida:

El sentido es universal y supratemporal. El sentido es potencialmente infinito, sin embargo, puede actualizarse solamente al tocar otro sentido (ajeno), aunque se trate de una pregunta en el discurso interior de aquel que comprende. Para poner de manifiesto los nuevos momentos de su infinitud, el sentido, lo mismo que la palabra que descubre sus significaciones solo en un contexto, debe cada vez entrar en contacto con otro sentido. (Bajtín, 2015, p. 139).

Tanto Gadamer como Bajtín parecen estar de acuerdo con el círculo que implica la actualización del sentido y la comprensión del mundo. Este se da por y en el lenguaje. Para Bajtín, en la triple relación de un "yo-para-mí, yo-para-otro, otro-para-mí" (Bubnova, 2006 p.103). El tercero en el dialogismo bajtiniano es lo social que coincide con la importancia de la historia en la hermenéutica en general. 


\section{La fusión de horizontes y la exotopía para fundamentar el diálogo}

Para Bajtín (2015), "el mundo es el horizonte de mi conciencia que procede y actúa [...] el mundo es el objeto del acto, del acto-pensamiento, acto-sentimiento, acto-palabra" (p.101) ${ }^{2}$, es decir que el horizonte es el lugar y el tiempo en el que el ser acontece de manera inconclusa, abierta, en donde el sentido no es dado, sino construido. Además del mundo, hay otros horizontes: los que emergen de la exotopía: "Al contemplar como un todo a una persona que se encuentra afuera y frente a nosotros, nuestros horizontes concretos, realmente vividos no coinciden [...]. Al mirarnos uno al otro, dos mundos distintos se reflejan en nuestras pupilas" (Bajtín, 2015, p. 25). ${ }^{3}$ Ese excedente de visión, que está dado por el cuerpo exterior del otro, por esa frontera, está condicionado por el tiempo y el espacio, pues nadie puede ocupar nuestro lugar, es único y singular. Desde nuestros horizontes tenemos un encuentro con el otro, con lo otro. Es desde nuestra mirada que observamos la completud del cuerpo del otro, lo que este no puede observar desde su cuerpo interior y lo que el otro percibe de mí, que es inaccesible desde mi interior. Los horizontes exotópicos permiten comprender al otro desde el propio lugar, y en un movimiento al como si del lugar del otro para regresar a mí mismo: "No se puede concebir la comprensión como una empatía y como colocarse en un lugar ajeno (pérdida del lugar propio)" (Bajtín, 2015, p. 137).

Para Bajtín (2015) la exotopía es el mecanismo de comprensión más poderoso porque desde los horizontes de sentido, se establece un diálogo que les amplía y renueva. Gadamer (2004) no está muy lejos de esta concepción cuando explica la interpretación - pues para él interpretar es ya comprender-y en relación a los horizontes:

La interpretación no es ninguna descripción por parte de un observador "neutral", sino un evento dialógico en el cual los interlocutores se ponen en juego por igual y del cual salen modificados; se com-

2 El resaltado es propio.

3 Ibid. prenden en la medida en que son comprendidos dentro de un horizonte tercero, del cual no disponen sino en el cual y por el cual son dispuestos. (Vergara, 2011, p. 78). ${ }^{4}$

Si con Bajtín (2015) advertimos la complejidad de la comprensión en la exotopía en nuestras fronteras corporales inscritas en el mundo de la vida, con Gadamer (2004) reconocemos las tensiones propias de la comprensión y la inminencia de, al menos, tres horizontes: el tuyo, el mío, el de la historia en la cual y por la cual somos dispuestos. Para Gadamer (2004), la traducción resulta un modelo para mostrarlo: "se funden los horizontes de pasado y presente en un constante movimiento como el que constituye la esencia de la comprensión" (p. 373) y eso es el lenguaje mismo, un círculo hermenéutico. La fusión de horizontes es aquello que se hace común desde lo propio y lo ajeno, en la periferia del yo y el tú, en marco de lo otro.

Estas cuestiones nos remiten a las dimensiones ética y estética de los actos, todos los actos dirigidos a otros, siendo algunos de ellos los de la palabra y la escucha, nunca desligados de lo social y lo histórico, por tanto, profundamente ideológicos y cargados de incertidumbres y opacidades, de malentendidos e incomprensiones del diálogo inconcluso que es la vida misma. En palabras de Cárdenas y Ardila (2009), "la verdad y el saber y todos los productos del pensamiento humano no están en la cabeza de un solo hombre, sino que obedecen a las permanentes discusión y búsqueda por medio de la comunicación dialógica” (p. 42).

El diálogo como existencia: entre Buber y Gadamer

Se cuenta que un hombre inspirado por Dios fue una vez desde el dominio de las criaturas hasta el gran vacío. Anduvo hasta que llegó a las puertas del misterio. Golpeó. Desde adentro le gritaron: “Qué quieres aquí?" Y dijo: "He difundido tu alabanza en los oídos de los mortales, pero no me oyeron. Así que acudo a ti para que me oigas y respondas".

"Vuelve", le dijeron desde el interior, "que aquí no hay oídos para ti. En la sordera de los mortales he puesto mi escucha".

Buber (2006, p. 141).

4 El resaltado es propio. 
Porque el problema de la escucha es un problema de la comprensión y la compresión es dialógica, hacemos una posible conjunción entre la hermenéutica de Gadamer y la dialógica de Buber, a quien el alemán reconoció con su aporte para pensar la conversación. Para Vilanou (2002), es necesario revisar dónde nace la hermenéutica, pues se considera una disciplina de las ciencias del espíritu, cuyo propósito es interpretar y comprender el acontecer humano, como ya se ha explicado. En tanto doctrina de la interpretación, la hermenéutica permite repensar la Bildung, siendo Gadamer uno de sus principales exponentes. Vilanou (2002) explica cómo el pensamiento de este filósofo, teólogo y crítico alemán es una polifonía entre el idealismo de Platón y Hegel, la filosofía de Heiddeger y el Romanticismo de Hölderin. Toda esa suma de voces confluye en la apuesta de Gadamer por el aprecio del diálogo y la escucha para lograr la comprensión. Recordemos que para ellos esta es el centro de la existencia: autocomprensión, constitución ontológica e histórica: "la historia no nos pertenece, nosotros le pertenecemos a ella" (Vilanou, 2002, p. 214).

¿Cómo comprendernos a nosotros mismos?, ¿cómo darnos cuenta de nuestra propia formación?, ¿cómo comprender al otro, al mundo, a la historia? Para Gadamer hay un juego abierto a las interpretaciones, por eso critica la pretensión de una verdad absoluta y formula su hermenéutica como "la capacidad de escuchar a otra persona pensando que puede tener razón"5 (Vilanou, 2002, p. 218), esto es, reconocer una posible superioridad del interlocutor. Por eso, oír (que es la palabra así traducida) ${ }^{6}$ implica una postura ética que permite dejarse llevar por la actividad de la cosa ya que "a través de la audiencia no cabe adoptar una actitud dominadora" (Vilanou, 2002, p. 216). Esa postura ética dialógica nos deja ver los valores humanistas y la razón práctica que no es otra cosa que la vivencia de la hermenéutica.

5 El resaltado es propio.

6 No ahondaré en este documento sobre la ya consabida diferencia entre oír y escuchar. En la traducción de Gadamer parecen ser usados como sinónimos, siempre orientados a la comprensión.
Empezamos este apartado con un epígrafe inspirador de Martín Buber, que da cuenta de lo explicado por Gadamer: es que en la sordera de los mortales está la escucha, es decir, la práctica viva del lenguaje está en el mundo cotidiano y la escucha, el diálogo, está en su misma falta o ausencia. Está en la escuela, en el camino al trabajo y Buber va mucho más allá acerca de esta apertura dialógica con el universo: él incluye nuestra relación -o no relación- con Dios, con los animales y la naturaleza, además del otro y del sí mismo. Para Buber (2006), el diálogo puede darse sin la mediación del lenguaje -cuestión que a un lingüista perturba-, porque el lenguaje así entendido por el filósofo judío, es más que palabra, es una condición de existencia y de apertura cosmológica, una actitud:

Así como hablar solícitamente uno con otro no constituye una conversación (tal como lo demuestra a las claras ese raro deporte de personas más o menos dotadas intelectualmente, que con justeza se llama "discusión” o "confrontación”), para una conversación no se precisa ningún sonido, y ni siquiera ningún gesto. El lenguaje puede renunciar a toda manifestación sensible y sigue siendo lenguaje. (p.125).

Tanto Gadamer como Buber vuelven a la búsqueda del sentido para comprender el mundo en la dimensión dialógica, reflexiva y crítica que ello exige. Al respecto de la conversación y de la apertura dialógica, Gadamer (2011) advierte:

Estamos justamente en medio de lo que yo considero un punto de vista decisivo también en mi propio mundo filosófico, a saber, que el lenguaje solo se realiza plenamente en la conversación: también para el maestro, ser realmente capaz de ello es solo una posibilidad limitada. Es completamente claro que determinadas unidades del plan de estudios deben ser respetadas, pero lo decisivo es, sin embargo, que a la postre se dé al adolescente la capacidad de enmendar sus propias carencias de saber a través de su propia actividad. El educarse debe consistir ante todo en potenciar sus fuerzas allí donde uno percibe sus puntos débiles y en no dejarlos en manos de la escuela o, menos aún, confiarlo a las calificaciones que 
constan en los certificados o que, acaso, los padres recompensan. (p. 98).

Podría pensarse, a la ligera, que hay una total contradicción entre la apuesta de Buber y de Gadamer sobre la idea de conversación, pero no es así. Si revisamos bien, hablar sin escuchar, hablar solícitamente no es comprender ni interpretar. Y la plena realización del lenguaje como totalidad se manifiesta en la conversación como responsabilidad y autonomía en lo que el filósofo alemán llama la educación es educarse. Además, respecto a la observación de Buber (2006) sobre "ese raro deporte de personas más o menos dotadas intelectualmente" Gadamer (citado por Vilanou, 2002) reitera: “Todos somos auditorio, debemos aprender a escuchar, en uno u otro camino, a luchar siempre contra el ensimismamiento y eliminar el egoísmo y el afán de imposición de todo impulso intelectual" (p. 219).

En lo que tal vez no estén de acuerdo estos dos filósofos es en la idea de lenguaje. Para Gadamer, dice Vilanou (2002), "solo hay comprensión en la palabra porque la palabra es comunicación en su forma más pura: comprendemos un mundo 'empalabrado' ya que únicamente comprendemos un pensamiento empalabrado" (p. 219). Ello significa que la pedagogía hermenéutica de Hans George Gadamer está centrada en el logos, en la palabra, en la relación pensamiento-lenguaje, este último como potencia: cuanto más conocemos su variedad, mayor es la comprensión. De ahí la importancia que le da el filósofo alemán al aprendizaje de muchas lenguas y a la lengua materna, también a la formación humanista de la literatura, el arte, las ciencias y las matemáticas.

Desde esa perspectiva, la pedagogía hermenéutica ubica el diálogo en el centro de la formación para la comprensión del mundo, de la historia y de sí mismo. Esto podría referir varios estadios de diálogo también, de acuerdo con lo que ya hemos explicado y un nivel de autonomía y autocomprensión en el que el ser mismo es quien se forma. Para Buber, el dialogismo es actitud ante la existencia y los conceptos de responsabilidad y de amor están muy cercanos a la propuesta de Bajtín:
Solo hay responsabilidad auténtica cuando hay respuesta verdadera. ¿Respuesta a qué? [...] Respondemos al momento, pero al mismo tiempo respondemos por él, respondemos para él. Se nos pone en los brazos un concreto universal recién creado. Y respondemos por él. Un perro te ha mirado, respondes a su mirada; un niño te ha tomado de la mano, respondes a su contacto; una muchedumbre se mueve a tu alrededor, respondes a sus necesidades. (Buber, 2006, p. 143).

Es decir, la responsabilidad es una responsividad al universo, a la existencia misma con todo lo que le acontece: y si esa es la apuesta dialógica de la vida, ¿cuál es la de la educación? Una pedagogía, sin duda alguna, del espíritu y de las ciencias; vertida al diálogo y a la conversación, no solo como palabra sino como actitud de escucha del mundo de la vida, para nosotros, una formación de seres escuchantes, en tanto dialógicos, por la palabra y no solamente a través de ella.

\section{Diálogo como formación:}

\section{comprensión respondente}

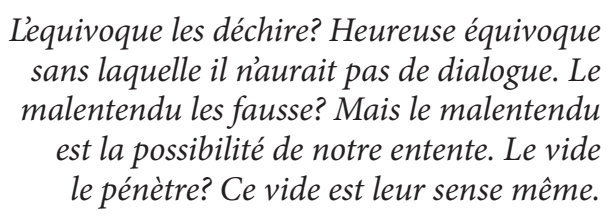

Blanchot (citado por Ponzio,1998, p. 202).

Con Blanchot volvemos a lo que ya dijimos con Buber, la falta, la ausencia y el vacío de la comprensión, de la escucha, le reclaman y posibilitan. Gadamer (2004) lo llamó la incapacidad para el diálogo. Y es que el monólogo también está en el lenguaje, Ponzio (1998) lo expresa cuando dice que este "no es solamente encuentro con el otro, comprensión respondente, enunciación, única e infinitamente varia: es también imposición de significados generales, repetición, cancelación de las diferencias, universalización sin ninguna referencia ni al yo ni al otro" (p. 202). Nuestra incapacidad para dialogar no solo reside en nosotros mismos, es la razón de que las palabras y el lenguaje no sean neutrales. Llevan en sí una carga ideológica, por ello, "podemos responder solo a palabras que nos implican en el plano del comportamiento y de la ideología" (Voloshinov, citado por Ponzio, 1998, p. 128). 
Es decir, no siempre nos metemos en un diálogo, aunque no podamos escindirnos de lo dialógico que implica la existencia, pero un monólogo, para Bajtín (2015) es sordo ante la respuesta ajena.

Como se habrá notado, el diálogo en cuanto formación o Bildung, como lo hemos explicado, requiere de mayor reflexión, especialmente cuando implica pregunta y respuesta en la incertidumbre de la comprensión. Sigamos a Buber (2006) para expresar ¿respuesta a qué?, ¿a quién?, ¿preguntar qué?, ¿pregunta de quién? Gadamer se preocupa más por la pegunta, Bajtín y Buber se interesan, en cambio, por la respuesta. Pero es necesario comenzar por la respuesta en cuanto acto ético y "expresión como solicitud de comprensión respondente, como se da en la palabra viva que se ofrece a la escucha" (Ponzio, 1998, p. 221).?

La comprensión respondente a la que se refiere Ponzio (1998) puede leerse en dos perspectivas. La primera es el acto ético y de sentido que implica la responsabilidad, la capacidad de respuesta ante el otro de la que no podemos escapar: "el sentido tiene carácter de respuesta. El sentido siempre contesta ciertas preguntas. Aquello que no contesta nada se nos presenta como falso de sentido, como sacado del diálogo" (Bajtín, 2015, p. 139). En esta filosofía práctica, todos los actos, que son dirigidos siempre a otros, en el marco de la arquitectónica, son respuesta: "El acto es una respuesta a un acto anterior, que en cuanto a tal, tiene sentido, y al provocar una respuesta en el otro, genera otro sentido nuevo" (Bubnova, 2006, p. 103). Podemos reconocer aquí una convergencia con Gadamer (2004) que ya hemos advertido en todo el recorrido: "pero esto significa que el sujeto que comprende debe comprender la pregunta" ( $\mathrm{p}$. 112) para poder contestar, ¿cómo se logra?, ¿puede formarse en el diálogo? Si el diálogo es formación, trans-formación, entonces asentimos.

La segunda perspectiva es la situada en la palabra misma, como una realización del diálogo. Aquí la comprensión respondente es escucha y no solo frente a la alteridad, sino frente a la polifonía que ella carga:

7 El resaltado es propio.
La palabra no olvida el camino recorrido y no puede librarse del todo de esos contextos concretos de los cuales ha entrado antes a formar parte. Todo miembro de la comunidad lingüística se coloca ante la palabra, no ya como palabra neutral de la lengua, libre de intenciones, sino habitada por voces ajenas. El hablante recibe la palabra de una voz ajena. La palabra llega a su contexto, llena de intenciones ajenas. (Bajtín, citado por Ponzio, 1998, p. 117).

Así la escucha también es un círculo de comprensión hermenéutica, inconcluso que se amplía y actualiza, que trans-forma. Porque en la compresión respondente del otro no solo se escucha su voz que se fusiona con la propia en una construcción de los sentidos, sino que se escucha la polifonía de voces ajenas -especialmente de ese tercero, lo social, lo histórico- que están presentes en el sujeto.

Volvamos a la cuestión sobre quiénes preguntan y responden: los interlocutores de la palabra viva, en la que la escucha es el destino de la expresión:

En Levinas (también en Bajtín) la alteridad y la dialogía no son un privilegio de un signo en cuanto tal, sino que existen en la expresión que requiere la escucha, en la expresión de la palabra viva que solicita acogida a la palabra ajena. En este sentido, pero solo en este sentido, Levinas habla de "privilegio de la palabra viviente", destinada a la escucha, en relación a la palabra imagen. (Ponzio, 1998, p. 220).

Ese privilegio de la palabra viviente que se dirige siempre a la escucha, ratificamos, es conflictivo. Y más si los interlocutores están en la escuela. Solo por eso y porque la comprensión del mundo y del sí mismo requiere de la expresión y de la escucha, del diálogo en su realización más íntima, creemos en la necesaria formación de la escucha en la educación:

Pero hay en la situación del enseñante una especial dificultad para mantener la capacidad del diálogo a la que sucumbe la mayoría. El que tiene que enseñar cree que debe y puede hablar y cuanto más consistente y sólido sea su discurso tanto mejor cree poder comunicar su doctrina. [...] La incapacidad para el diálogo está aquí en el profesor, y siendo éste el auténtico transmisor de 
la ciencia, esa incapacidad radica en la estructura monologal de la ciencia y de la teoría moderna. (Gadamer, 2004, p. 207).

Gadamer se refiere al monólogo pedagógico que él mismo vivió con su maestro, pero ello también se debe a una apuesta epistemológica, si se cree que el saber que comunica el maestro contiene una estructura monologal, entonces es su deber hacerla diálogo. El profesor es modelo de escucha y él mismo, ¿está preparado para afrontar la incapacidad para el diálogo que nos es inherente?

La pedagogía espiritual de la que da cuenta Vilanou (2002), como respuesta a ese momento histórico, debe abrirse al mundo de los valores y la teleología como verdadero objetivo de la educación, diríase, a una ética y estética de la escucha, en la posibilidad del diálogo escolar. ¿Cuál es ese momento histórico, ese tercero de nuestro diálogo en el que somos? Para Cárdenas y Ardila (2009), la pedagogía debe ser crítica y basada en la respuesta; dialógica y polifónica; exotópica, creativa, que acoja la diversidad. Si maestro y estudiante somos seres en formación, pues estamos siempre inconclusos, entonces tenemos que actualizar nuestros horizontesy asumir, en este caso, la Colombia en la que estamos inscritos, para re-construir y trans-fomar.

\section{A manera de conclusión}

La pedagogía hermenéutica y de las ciencias del espíritu concibe la educación con la pretensión de un estatuto científico y espiritual que se transmite a través del amor. Y este punto hace énfasis: "El educador se caracteriza por una doble dimensión: amor a los valores culturales que ha de tener vivos en alma para poderlos transmitir y amor hacia el individuo en formación" (Vilanou, 2002, p. 213). Ese mismo amor, en el acto estético de contemplación del otro, es el que nos introduce en el acto ético, pues son indesligables. Bajtín (2015), tomando el ejemplo de quien sufre, dice: "el que yo lograra experimentar la postura vital de aquel que sufre me puede incitar a un acto ético: ayuda, consuelo, reflexión cognoscitiva" (p. 31). Esa experimentación puede darse por la escucha, no solo de quien sufre sino de quien enseña y de quien aprende, siendo el maestro el primero con conciencia de su excedente de visión sobre su estudiante, el que le introduce a la escuela -así como la madre introduce el hijo a la vida- y le nombra, en un encuentro de amor pedagógico, de amor que escucha y es escuchado.

En definitiva, este periplo que propusimos desde las ciencias del espíritu para la formación de la escucha en la educación es inconcluso, en tanto se constituye en un círculo -o quizás espiral- de comprensión hermenéutica y una construcción preliminar que atiende, más específicamente, a las configuraciones pedagógicas y didácticas de la escucha.

Así, pretendimos un diálogo entre los autores aquí reseñados y la apuesta por trascender, a partir de la reflexión teórica, la manera en la que concebimos la educación y el lenguaje, como punto de partida para pensar en la transformación de nuestras escuelas. Por lo mismo, más que conciliar los planteamientos de diversos autores, evidenciamos sus posibles confluencias acerca de la escucha, del diálogo y de la conversación a través de la palabra viva, los actos éticos y estéticos dela responsabilidad yla co-existencia en la fusión de horizontes, siempre en el marco de las malinterpretaciones propias del lenguaje.

Sugerimos, ante todo, una necesaria pero imposible tarea: formar-nos en la comprensión del sí mismo, del otro y de lo otro, la tríada de una escucha arquitectónica, hermenéutica y dialógica que nos llama a practicar la pedagogía del espíritu, la pedagogía de la escucha. 


\section{Referencias}

Alejos García, J. (2006). Identidad y alteridad en Bajtín. Acta poética, 27(1), 45-61. Recuperado de https://goo.gl/TW3A96. Bajtín, M. (2015). Yo también soy. (Fragmentos sobre el otro). Buenos Aires: Ediciones Godot.

Buber, M. (2006). Yo y tú y otros ensayos. Buenos Aires: Lilmod.

Bubnova, T. (2006). Voz, sentido y diálogo en Bajtín. Acta Poética, 27(1), 97-114. Recuperado de https:// goo.gl/gMU41q

Cavafis, C. (s.f.) Itaca. Ciudad Seva. Recuperado de http:// ciudadseva.com/texto/itaca/

Cárdenas, J. y Ardila, F. (2009). Lenguaje, dialogismo y educación. Folios, 29, 27-50. Recuperado de https:// goo.gl/KuL4Lm

Gadamer, H. (2004). Verdad y método II. Salamanca: Ediciones Sígueme.

Gadamer, H. (2011). La educación es educarse. Revista Santander, 6, 90-109. Recuperado de https://goo.gl/ qtnJeD
Gómez, J. (2013). La investigación de la subjetividad: entre la ficción y la verdad. En C. Piedrahita, A. Díaz y P. Vommaro (eds.) Acercamientos metodológicos a la subjetivación política: debates latinoamericanos (pp. 31-48). Bogotá: Universidad Distrital Francisco José de Caldas. Recuperado de https://goo.gl/DurSGy

Ponzio, A. (1998). La revolución bajtiniana. El pensamiento de Bajtín y la ideología contemporánea. Madrid: Ediciones Cátedra.

Vergara, J. (2011). Gadamer y la hermenéutica de la comprensión dialógica: historia y lenguaje. Revista de Filosofía, 69(3), 74-93. Recuperado de https:// goo.gl/JZfwUg

Vilanou, C. (2002). Formación, cultura y hermenéutica: de Hegel a Gadamer. Revista de Educación, 328, 205223. Recuperado de https://goo.gl/RLT7p9 